Jurnal ELKOM diterbitkan oleh Sekolah Tinggi Elektronika dan Komputer (STEKOM). Jurnal ELKOM sebagai sarana komunikasi dan penyebarluasan hasil penelitian, pemikiran serta pengabdian pada masyarakat

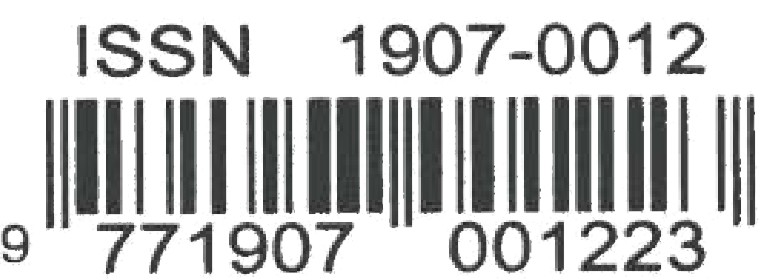

\begin{tabular}{lr}
\hline Perancangan Aplikasi Android Untuk Media Pembelajaran Budidaya Tanaman Secara \\
$\begin{array}{l}\text { Hidroponik Dengan Metode Demon-Disco Leaming } \\
\text { Daniel Novianto }\end{array}$ & $1-8$ \\
\hline $\begin{array}{l}\text { Rancangan Bangun Alat Musik Piano, Harpa, Marching Bell Digital Berbasis Arduino } \\
\text { Menggunakan Cahaya Laser Dan LDR } \\
\text { Dendy Kumiawan }\end{array}$ & $9-19$ \\
\hline $\begin{array}{l}\text { Rancangan Bangun Sistem Peringatan Dini Bencana Banjir Pada Sungai Tuntang Ke- } \\
\text { dungjati Berbasis Arduino Menggunakan Teknologi IOT }\end{array}$ & $20-30$ \\
\hline lhsan Hidayat Ardi & \\
\hline $\begin{array}{l}\text { Alat Pendeteksi Gas Amoniak Pada Kamar Mandi Berbasis Arduino( Studi Kasus Diho- } \\
\text { tel Wisma Menorah Sampangan Semarang) }\end{array}$ & $31-37$ \\
\hline $\begin{array}{l}\text { Achmad Abdul Charis } \\
\text { Rancang Bangun Alat Penyotiran Barang Otomatis Berbasis Arduino Pada PT Wahana }\end{array}$ & $38-44$ \\
Prestasi Logistik Semarang &
\end{tabular}

STEKOM

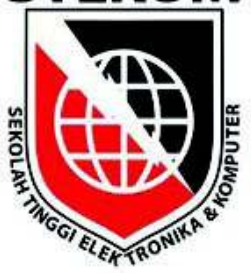

S $T$ E K O M Sekolah Tinggi Elektronika dan Komputer SEMARANG 


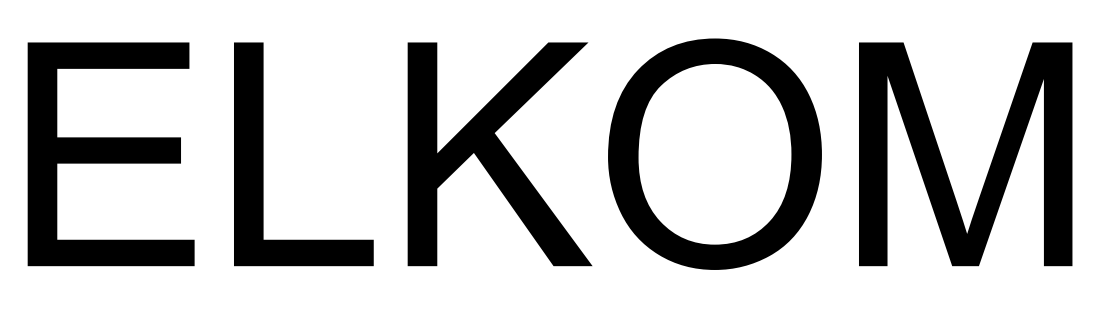

JURNAL ELEKTRONIKA DAN KOMPUTER

Penanggung Jawab :

Ketua Sekolah Tinggi Elektronika \& Komputer

Pemimpin Redaksi :

Sulartopo, S.Pd, M.Kom

Penyunting Pelaksana :

Dr. Ir. Drs. R. Hadi Prayitno, S.E, M.Pd

Dr. Ir. Agus Wibowo, M.Kom, M.Si, M.M

Sarwo Nugroho, S.Kom, M.Kom

Sekretaris Penyunting:

Ir. Paulus Hartanto, M.Kom

Mars Caroline Wibowo, S.T, MT. Tech

Sekretariat :

Dr. Unang Achlison, S.T, M.Kom

Djoko Soerjanto, S.E, M.Kom

Muhammad Sidik, S.Kom, M.Kom

Desain Grafis :

Setiyo Adi Nugroho,S.E, S.Kom

\footnotetext{
Alamat Redaksi :

Pusat Penelitian - Sekolah Tinggi Elektronika \& Komputer (STEKOM) Jl. Majapahit No. 605 Semarang Telp. 024-6710144 E-Mail :

elkom@stekom.ac.id
} 


\section{KATA PENGANTAR}

Puji syukur ke hadirat Tuhan Yang Maha Esa dengan terbitnya Jurnal elektronika dan computer (ELKOM) Edisi Desember 2018, Volume 11 Nomor 1 Tahun 2018 dengan artikel-artikel yang selalu mengikuti perkembangan IImu Pengetahuan dan Teknologi dalam bidang elektronika dan computer. Semua artikel yang dimuat pada Jurnal elektronika dan komputer (ELKOM) ini telah ditelaah oleh Dewan Redaksi yang mempunyai kompetensi di bidang elektronika dan komputer. Pada edisi ini kami menyajikan beberapa topik menarik tentang penerapan elektronika dan komputer yaitu: "Perancangan Aplikasi Android Untuk Media Pembelajaran Budidaya Tanaman Secara Hidroponik Dengan Metode Demon-Disco Learning ", serta "Rancang Bangun Alat Musik Piano, Harpa, Marching Bell Digital Berbasis Arduino Menggunakan Cahaya Laser Dan Ldr (Studi Kasus SMP NU 07 Brangsong) ", selanjutnya "Rancang Bangun Sistem Peringatan Dini Bencana Banjir Pada Sungai Tuntang Kedungjati Berbasis Arduino Menggunakan Teknologi IOT ", dan "Alat Pendeteksi Gas Amoniak Pada Kamar Mandi Berbasis Arduino (Studi kasus dihotel wisma menorah sampangan Semarang)". "Rancang Bangun Alat Penyortiran Barang Otomatis Berbasis Arduino Pada Pt Wahana Prestasi Logistik Semarang ", Terima kasih yang mendalam disampaikan kepada penulis makalah yang telah berkontribusi pada penerbitan Jurnal ELKOM edisi kali ini. Dengan rendah hati dan segala hormat, mengundang Dosen dan rekan sejawat peneliti dalam bidang elektronika dan komputer untuk mengirimkan naskah, review, gagasan dan opini untuk disajikan pada Jurnal elektronika dan komputer (ELKOM) ini. Sebagai akhir kata, saran dan kritik terhadap Jurnal elektronika dan komputer (ELKOM) yang membangun sangat diharapkan. Selamat membaca.

Semarang, Desember 2018 


\section{DAFTAR ISI}

Kata

Pengantar

Daftar

Isi. .ii

1. Perancangan Aplikasi Android Untuk Media Pembelajaran Budidaya Tanaman Secara Hidroponik Dengan Metode Demon-Disco Learning, Daniel Novianto 1-8

2. Rancang Bangun Alat Musik Piano, Harpa, Marching Bell Digital Berbasis Arduino Menggunakan Cahaya Laser Dan Ldr (Studi Kasus SMP NU 07 Brangsong), Dendy Kurniawan .9-19

3. Rancang Bangun Sistem Peringatan Dini Bencana Banjir Pada Sungai Tuntang Kedungjati Berbasis Arduino Menggunakan Teknologi IOT, Ihsan Hidayat Ardi.... 20-30

4. Alat Pendeteksi Gas Amoniak Pada Kamar Mandi Berbasis Arduino (Studi kasus dihotel wisma menorah sampangan Semarang), Achmad Abdul Charis 31-37

5. Rancang Bangun Alat Penyortiran Barang Otomatis Berbasis Arduino Pada Pt Wahana Prestasi Logistik Semarang, Yan IImas Puimera $38-44$ 


\title{
RANCANG BANGUN ALAT MUSIK PIANO, HARPA, MARCHING BELL DIGITAL BERBASIS ARDUINO MENGGUNAKAN CAHAYA LASER DAN LDR (Studi kasus : SMP NU 07 Brangsong)
}

\author{
Dendy Kurniawan \\ Sekolah Tinggi Elektronika dan Komputer (STEKOM) \\ JI. Majapahit 605 \& 304 Semarang, Indonesia \\ Email : humas@stekom.ac.id
}

\begin{abstract}
ABSTRAK
Alat musik merupakan suatu alat yang diciptakan untuk menghasilkan bunyi. Harga alat musik sendiri bermacam - macam tergantung jenis alat musik dan kualitas bahan yang digunakan untuk membuat alat musik tersebut. Di sekolah SMP NU 07 Brangsong belum mempunyai alat musik kecuali rebana. Hal tersebut dikarenakan tidak adanya dana untuk membeli sebuah alat musik. Pihak sekolah lebih mengalokasikan dana ke bangunan atau gedung sekolah dan bantuan beasiswa untuk anak kurang mampu dan anak yang cerdas. Dengan demikian murid - murid di sekolah tersebut tidak bisa berlatih atau mengasah kemampuannya dalam bidang musik. Dari masalah tersebut sebenarnya dapat terselesaikan dengan sebuah alat musik Piano, Harpa, Marching Bell Digital berbasis arduino menggunakan cahaya laser dan LDR. Karena alat ini dapat dibuat dengan biaya yang murah dan dapat berfungsi lebih dari satu alat musik. Sistem kerja dari alat ini yaitu terdapat beberapa sebuah laser akan memancarkan cahaya tepat pada sensor LDR (berpasang - pasang). Dan ketika sepasang sinar laser dan LDR nomer satu terhalang oleh suatu benda atau tangan maka akan mengeluarkan suara piano bernotasi "DO". Selanjutnya ketika sepasang sinar laser dan LDR nomer dua terhalang akan mengeluarkan suara piano bernotasi "RE" dan seterusnya. alat ini juga dilengkapi dengan tombol yang berfungsi sebagai pemilih jenis suara yang akan dihasilkan dan oktaf yang diinginakan.
\end{abstract}

Kata Kunci : Alat musik, Arduino, DFPlayer, Laser, LDR

\section{PENDAHULUAN}

SMP NU 07 Brangsong adalah suatu sekolah swasta yang berada di Desa Blorok Kecamatan Brangsong Kabupaten Kendal. Gedung SMP NU 07 Brangsong awalnya hanya menumpang pada sekolah madrasah yang ada di Desa Blorok dan bangunan - bangunan yang sudah tidak terpakai namun masih layak di tempati seperti rumah kosong. Tahun demi tahun SMP NU 07 Brangsong dapat membangun gedung sendiri walaupun masih kecil dan sebagian besar masih menumpang di gedung madrasah. Pembangunan gedung sangat terkendala oleh ketidak adaannya dana.Pengajuan proposal permohonan dana ke Dinas selalu ditolak. Sedangkan Dana Bantuan Operasional Sekolah (BOS) yang diperoleh tiga bulan sekali digunakan untuk honor para guru dan karyawan serta untuk menunjang ekstra kulikuler dan kegiatan belajar mengajar keseharian. Sedangkan untuk dana pembangunan gedung dan pembelian alat musik menggunakan dana komite yang dibayar siswa sebesar $R p$. 35.000,- per bulan. Berikut tabel pemasukan dan pengeluaran keuangan SMP NU 07 Brangsong per bulan yang diperoleh dari hasil wawancara penulis terhadap staf Tata Usaha. 
Adapun dana Lain - lain digunakan untuk tambahan jika di bulan tertentu jenis pengeluaran melebihi anggaran yang telah di tentukan. Dan juga digunakan untuk perbaikan gedung atau pembangunan serta pelengkapan dan pemeliharaan alat musik atau alat praktek di SMP NU 07 Brangsong. Alat musik di sekolah SMP NU 07 Brangsong pun belum memadahi. Dapat dilihat dari setelah sekian puluh tahun sekolah ini berdiri, hanya memiliki satu jenis alat musik yaitu rebana. Padahal siswa - siswi yang sekolah di SMP NU 07 Brangsong selain mendapatkan pelajaran teori, mereka juga harus mendapatkan pelajaran praktek kesenian, dalam hal ini kesenian musik melodi. Meskipun seperti itu pihak sekolah dalam wawancara yang di lakukan oleh penulis menjelaskan untuk saat ini pihak sekolah ingin menambah jumlah ruang kelas dan melengkapi buku perpustakaan ketimbang membelikan alat musik yang harganya mahal dan sebenarnya juga dibutuhkan oleh murid - murid untuk melatih bakat melatih melodi. Dan terdapat juga murid - murid yang meminta kepada guru kesenian bahkan kepada kepala sekolah untuk di belikan suatu alat musik selain rebana. Harga alat musik sungguhan bersasarkan situs jual beli online yang di cari oleh penulis dapat di lihat pada tabel dibawah ini.

Total harga dari ketiga alat musik tersebut yaitu Rp. 87.200.000,terbilang "Delapan Puluh Tujuh juta Dua Ratus Ribu Rupiah". Dari masalah tersebut sebenarnya dapat terurai dengan pembuatan sebuah alat musik yang harganya murah namun dapat digunakan sebagai media praktek bagi siswa - siswi dan menghasilkan suara yang sama dengan alat musik sungguhan.

\section{LANDASAN TEORI}

\subsection{Alat Musik}

Alat musik menurut heru setiawan (2011) adalah suatu instrumen yang dibuat atau dimodifikasi untuktujuan menghasilkan musik. Pada prinsipnya, segala sesuatu yangmemproduksisuara, dan dengan cara tertentu bisa diatur oleh musisi, dapat disebut sebagai alatmusik.

a. Piano

Menurut Van E. dan Lea Piano adalah salah satu alat musik yang menggunakan papan tuts dan bekerja dengan cara perkusi (diketuk), menggunakan jari-jari tangan. Orang yang memainkan alat musik ini disebut pianis. Jika dibandingkan dengan alat alat musik lainnya, piano terbilang alat musik yang mahal dan tergolong langka sehingga tidak semua orang bisa memainkannya.

\section{b. Harpe}

Harpe, arpa menurut Ds. Soewito merupakan alat musik petik sejenis kecapi yang berdawai banyak. Harpe termasuk alat musik tua, berfungsi ganda yang dapat digunakan untuk melodis dan ritmis. Di tanah air kita musik seperti ini tidak banyak dijumpai. Di India alat musik ini digunakan sebagai musik symphonie.

\section{c. Marching Bell (Bellyra)}

Diambil dari teori skripsi Galas Sangaluh Padmanaba (2014) Bellyra Adalah alat musik melodi drum band yang terdiri dari bilah-bilah logam persegi (lyra) yang setiap logam memiliki nada tersendiri, dan dimainkan dengan cara dipukul dengan stik yang ujungnya terbuat dari mika. Fungsi utama bellyra adalah memainkan nada-nada melodi, yakni nada-nada lagu yang dimainkan oleh unit drum band sehingga pemirsa dapat menentukan / menebak lagu apa yang sedang dimainkan.

\subsection{Pengertian Arduino 2560}


Arduino Mega 2560 adalah papan mikrokontroler berbasis

ATmega2560. Yang mempunyai 54 pin digital input / output, di mana 14 pin dapat digunakan sebagai output PWM, 16 analog input, 4 UARTs (hardware serial ports), $16 \mathrm{MHz}$ crystal oscillator, sambungan USB, power jack, ICSP header, dan tombol reset. Board ini juga menggunakan daya yang terhubung ke komputer dengan kabel USB atau daya eksternal dengan adaptor ACDC atau baterai.

\subsection{LDR (Light Dependent Resistance) Module}

\section{a. Pengertian LDR Module}

LDR (Light Dependent Resistance) adalah resistor yang dapat berubah ubah nilai resistansinya jika permukaannya terkena cahaya.Kondisinya ialah jika terkena cahaya nilai resistansinya kecil, sedangkan jika tidak terkena cahaya (kondisi gelap) maka nilai resistansinya besar. Dalam keadaan gelap resistansi LDR sekitar $10 \mathrm{M} \Omega$ dan dalam keadaan terang sebesar $1 \mathrm{~K} \Omega$ atau kurang. LDR tersebut dari bahan semikonduktor seperti kadmium sulfida. Dengan bahan ini energy dari cahaya jatuh menyebabkan lebih banyak muatan yang dilepas atau arus listrik meningkat. Artinya resistansi bahan telah mengalami penurunan. Dengan sifat LDR yang demikian, maka LDR dapat digunakan sebagai sensor cahaya

\section{b. Prinsip kerja Laser dengan LDR \\ Module}

Dari masing - masing penjelasan dari laser dan LDR diatas dapat dimanfaatkan sebagai berikut. Laser digunakan sebagai penyalur atau sumber cahaya yang di sorotkan ke LDR module. Sedangkan LDR Module bertugas sebagai sensor cahaya. LDR dipasang sedikit menjorok kedalam agar tidak menangkap cahaya lingkungan terlalu banyak seperti gambar 2.4.2.1 Jika LDR module menerima cahaya laser maka LDR module akan mengeluarkan sinyal podsitif atau I dan akan diproses oleh arduino.

\subsection{Speaker}

Speaker atau loudspeaker adalah sebuah komponen elektronika yang berfungsi untuk mengubah getaran listrik menjadi getaran suara. Loud speaker terdiri dari kumparan yang terpasang pada diafragma dan kemudian kumparan tersebut dialiri arus sehingga menjadi elektromagnet, kumparan tadi akan tertarik kedalam atau keluar, tergantung dari aras arus dan polaritas magnetnya, karena kumparan dipasang pada diafragma maka setiap gerakan kumparan akan menggerakkan diafragma secara bolak - balik sehingga membuat udara bergetar yang akan menghasilkan suara.

\subsection{Adaptor}

Menurut Wikipedia, Adaptor adalah sebuah rangkaian yang berguna untuk mengubah tegangan $A C$ yang tinggi menjadi DC yang rendah. Adaptor merupakan sebuah alternatif pengganti dari tegangan DC seperti ;baterai, Aki karena penggunaan tegangan $A C$ lebih lama dan setiap orang dapat menggunakannya asalkan ada aliran listrik di tempat tersebut.

\subsection{Bahasa Pemprograman C}

Banyak bahasa pemrograman yang biasa digunakan untuk program mikrokontroler, misalnya bahasa assembly. Namun dalam pemrograman arduino bahasa yang digunakan adalah bahasa $\mathrm{C}$. Bahasa C menghasilkan file kode objek yang 
sangat kecil dan dieksekusi dengan sangat cepat. Karena itu, Bahasa C sering digunakan pada sistem operasi dan pemrograman mikrokontroler. Bahasa C adalah multi-platform karena bahasa $\mathrm{C}$ bisa diterapkan pada lingkungan windows, Unix, Linux, atau sistem operasi lain tanpa mengalami perubahan source code. Karena arduino menggunakan bahasa $\mathrm{C}$ yang multi-platform, software arduino pun bisa dijalankan pada semua sistem operasi yang umum, misalnya Windows, Linux dan MacOS.Di internet banyak Library Bahasa $C$ untuk arduino yang bisa didownload dengan gratis.Setiap library arduino biasanya disertai dengan contoh pemakainnya.Keberadaan librarylibrary ini bukan hanya membantu kita membuat proyek mikrookontroler, tetapi bisa dijadikan sarana untuk mendalami pemrograman Bahasa $\mathrm{C}$ pada mikrokontroler. (Muhammad Syahwil, 2013)

\subsection{Penguat (Amplifier)}

Penguat (Amplifier) adalah rangkaian komponen elektronika yang dipakai untuk menguatkan daya (atau tenaga secara umum). Dalam bidang audio, amplifier akan menguatkan signal suara berbentuk analog dari sumber suara yaitu memperkuat signal / gain arus dan tegangan listrik berbentuk sinyal $A C$ dari inputnya menjadi arus listrik AC dan tegangan yang lebih besar, juga dayanya akan menjadi lebih besar di bagian outputnya.

\subsection{Echo}

Echo merupakan salah satu didalam delay effects. Delay Effects Sendiri adalah pilihan yang dapat digunakan untuk memperkenalkan serangkaian mengulangi atau gema delayer dari sinyal input asli pada interval secara berkala. Sedangkan echo adalah sebuah rangkaian elektronika yang berfungsi untuk menimbulkan serangkaian suara ulang, atau menambahkan gema untuk suara. Sehingga suara yang di hasilkan menjadi memantul panjang.

\section{METODE PENELITIAN}

\subsection{Blok Diagram Rangkaian}

Salah satu bagian terpenting dalam perancangan suatu alat adalah Blok diagram sistem, karena dari blok diagram rangkaian inilah dapat diketahui cara kerja rangkaian keseluruhan. Sehingga keseluruhan blok diagram rangkaian tersebut akan menghasilkan suatu sistem yang dapat difungsikan atau dapat bekerja sesuai dengan perancangan.

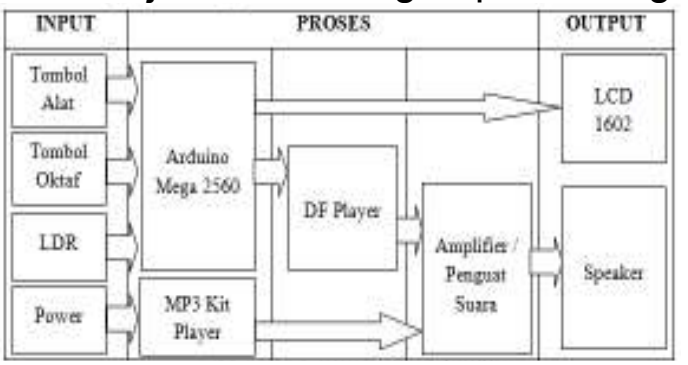

Gambar 3.1.1 Blok Diagram Rangkaian

\subsection{Flowchart}




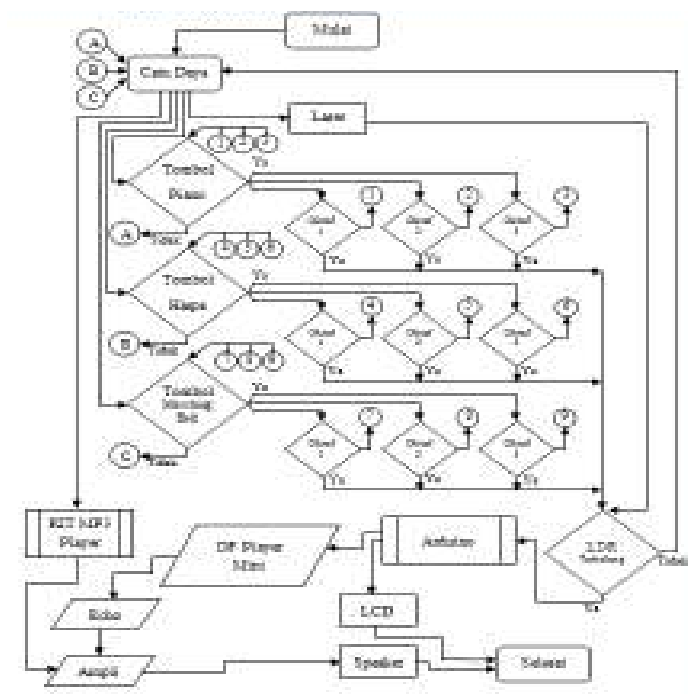

Gambar 3.2.1 Flowchart

Prinsip dasar alat ini adalah memutar file MP3 yang di simpan di memori mmc berdasarkan nilai LDR yang tidak terkena cahaya (gelap) dan pernyataan yang di inputkan oleh user menggunakan tombol alat musik dan tombol oktaf. Sedangakn LCD disini menjelaskan alat musik dan oktaf keberapa yang sedang di mainkan saat ini. Sedangkan Kit Mp3 digunakan sebagai pengiring atau pemutar mp3 lainnya yang disimpan di flasdisk. Alat ini adalah sebagai pengganti alat musik sungguhan yang harganya lebih mahal di bandingkan alat musik yang di buat oleh peneliti.

\subsection{FOD (Flow Of Document)}

\section{a. Sistem Lama}

Sistem kerja alat musik harpa yaitu dengan memanfaatkan senar atau dawai yang di bentangkan dengan ukuran tekanan yang berbeda untuk membedakan antara bunyi satu dengan yang lainnya. Prinsip kerjanya alat musik piano sebenarnya sama dengan harpa, yaitu berasal dari dawai yang jumlahnya banyak. Yang terletak dikotak kayu yang juga merupakan alat resonasi. Apabila tuts ditekan, maka palu-palu kecil memukul dawai-dawai tersebut, sehingga mengeluarkan getaran suara. Sistem kerja marching bell sendiri yaitu dengan memanfaatkan suara yang berasal dari getaran balok logam persegi yang ukurannya berbeda - beda dan dengan cara di pukul menggunakan stik yang terbuat dari plastik mika keras.

\section{b. Sistem Baru}

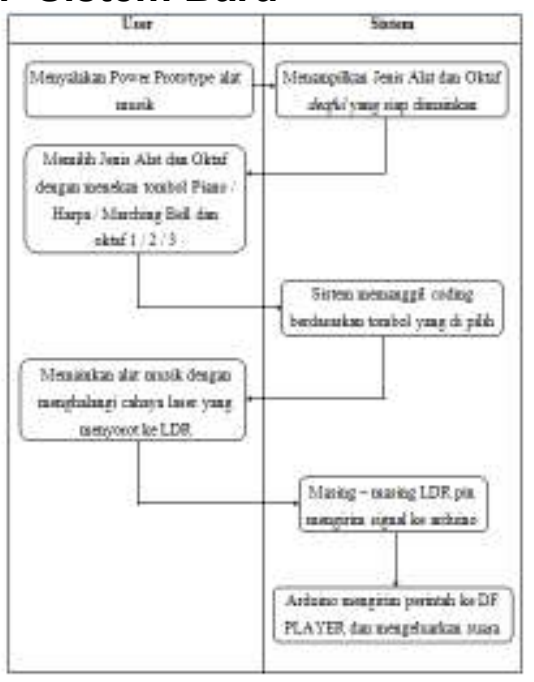

Gambar 3.3.1 FOD Sistem Baru

Didalam pembuatan alat musik tiruan ini penulis memanfaatkan cahaya laser sebagai pengganti snar dan nilai Idr untuk inputan data yang akan diproses oleh arduino. Selain itu penulis juga memanfaatkan fungsi push button sebagai pernyataan inputan alat musik yang dipilih dan oktaf yang dipilih. Output dari arduino yaitu berupa LCD display untuk menampilkan jenis alat musik dan oktaf yang dipilih serta perintah terhadap DF player mini untuk memutar MP3 yang di simpan di mmc berdasarkan nilai LDR yang di peroleh oleh arduino. Jadi untuk perawatan sendiri tidak serumit seperti merawat harpa, piano atau marching bell. Mp3 Kit dapat digunakan sebagai pemutar lagu atau musik pengiring.

\section{HASIL DAN PEMBAHASAN \\ 4.1 Harga Komponen}


Tabel 4.1.1 Daftar Harga Komponen yang di Gunakan

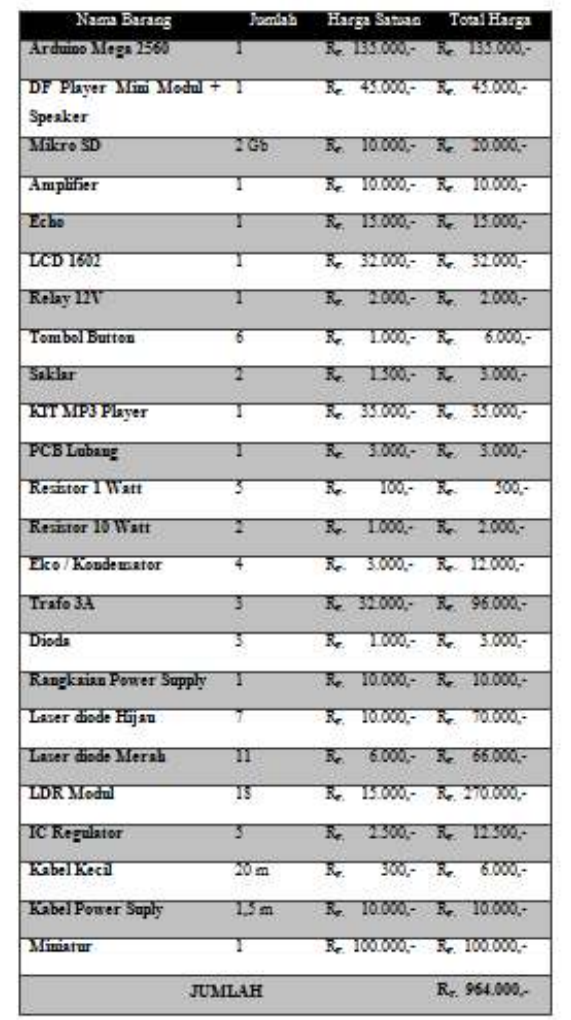

Total harga dari keseluruhan komponen tersebut yaitu Rp. 964.000,terbilang "Sembilan Ratus Enampuluh Empat Ribu Rupiah".

\subsection{Pengujian Tombol dengan LCD 1602}

Dari pengujian yang dilakukan penulis dapat di peroleh hasil yaitu adanya kesesuaian atau keberhasilan dari keselruhan tombol baik tombol pemilih alat musik atau tombol pemilih oktaf dengan LCD 1602. Jika di tekan tombola lat musik piano maka LCD menampilkan tulisan "Piano", begitu juga dengan tombol yang lainnya.

\subsection{Pengujian LDR Module}

Dari pengujian LDR module dapat disimpulkan bahwa Idr modul masing - masing akan mengirimkan signal ke arduino mega 2560 berdasarkan cahaya cahaya laser yang diterimanya. Jika LDR menerima sinar laser, maka LDR tidak akan mengirimkan signal ke arduino atau "0" dan jika LDR tidak menerima cahaya laser maka LDR akan mengirimkan signal ke arduino atau "1".

\subsection{Pengujian Amplifier dan Speaker}

Pengujian Amplifier dan speaker dilakukan dengan dua ctahapan. Tahapan yang pertama yaitu menyam-bungkan langsung speaker ke DF Player mini modul dan tahapan yang ke dua yaitu output suara dari DF Player disambungkan ke amplifier kemudian output suara amplifier di sambungkan ke speaker. Dari hasil pengujian dapat di simpulkan bahwa suara yang dihasilkan lebih keras menggunakan Ampli-fier dibandingkan tanpa menggunakan amplifier.

\subsection{Pengujian KIT MP3 Player}

Pengujian KIT MP3 Player dilakukan dengan beberapa cara. Cara yang pertama yaitu menguji input an mulai dari Flasdisk, MMC dan jack AUX. ketigan input an tersebut masuk kedalam tombol "Mode" di MP3 Kit Player. Cara yang kedua yaitu menguji tombol Next. Sedangkan cara berikutnya yaitu menguji tombol volume + dan volume - . Hasil pengujian keseluruhan dengan skema ini yaitu dapat di simpulkan adanya kesesuaian atau keberhasilan.

\subsection{Pengujian Echo}

Pengujian Echo dilakukan dengan dua tahapan. Tahapan yang pertama yaitu menyambungkan langsung DF Player mini modul ke amplifier tanpa melalui echo dan tahapan yang ke dua yaitu output suara dari DF Player disambungkan ke Echo kemudian output suara echo di sambungkan ke amplifier. Dari hasil pengujian dapat di simpulkan bahwa 
suara yang dihasilkan menggunakan Echo lebih bisa memantul atau bergema dibandingkan tanpa menggunakan echo.

\subsection{Pengujian Suara Notasi Nada}

Pengujian disini dilakukan dengan mencoba memainkan masing masing alat musik dan oktaf beserta menghalangi satu per satu sepasang sinar laser dengan LDR mulai dari urutan terbawah (Piano Oktaf 1 notasi Do rendah) sampai urutan tertinggi (Piano Oktaf 3 notasi $\mathrm{Fa}$ tinggi). Hal tersebut juga dilakukan pada uji coba alat musik Harpa dan Marchingbell. Hasil yang dicapai seharusnya yaitu setiap notasi semakin ke kanan maka semakin tinggi nadanya atau lebih tinggi dari pada notasi di sebelah kirinya dan suara masing - masing alat musik harus menyerupai suara alat musik sungguhan. Hasil pengujian dengan skema ini dapat disimpulkan bahwa hasil yang di capai sangat sempurna, semua notasi nada alat musik Piano, Harpa dan Marching bell pada Oktaf 1, oktaf 2 dan oktaf 3 tidak terdapat kesalahan atau dapat dikatakan sesuai.

\section{SIMPULAN DAN SARAN}

\subsection{Kesimpulan}

Kesimpulan dari penelitian yang telah dilakukan antara lain, yaitu :

1. Dalam pembuatan alat musik tiruan ini disimpulkan bahwa adanya kesesuaian antara permasalahan dengan solusi. Hal tersebut dibuktikan berdasarkan hasil validasi yang telah dilakukan pada ahli pakar desain dan ahli pakar materi yang menghasilkan angka yang menentukan hasil pada sistem baru tersebut, yaitu validasi pada ahli pakar desain dan ahli pakar materi menghasilkan nilai 3,7 yang artinya "Sangat Valid" dan validasi user menghasolkan angka 3,78 yang artinya "Sangat Efektif".

2. Harga alat musik sungguhan sangat mahal, hal itu dibuktikan dari harga alat musik di toko online yang penulis cari, yaitu harga alat musik Piano adalah Rp. 58.500.000,- , sedangkan harga alat musik Harpa adalah Rp. 28.000.000,- dan harga alat musik Marching Bell adalah Rp. 700.000,-. Jadi total keseluruhan harga alat musik sungguhan yaitu sebesar Rp. 87.200.000,- . sedangkan alat musik yang di ciptakan oleh penulis yaitu seharga Rp. 964.000,--

3. Menurut Bapak Siswadi, S.Pd guru seni budaya di SMP NU 07 Brangsong Suara yang dihasilkan dari alat musik tiruan ini sama dengan suara alat musik sungguhan.

\subsection{Keterbatasan Produk}

Rancang bangut alat musik piano, harpa, marchingbell digital ini masih ditemukan kekurangan yaitu sebagai berikut :

1. Suara dan speaker kurang halus dan kurang kurang keras.

2. Beberapa sensor LDR kurang sensitive.

3. Tidak dilengkapi dengan demo permainan alat musik secara otomatis.

4. Alat musik tiruan hanya bisa digunakan sebagai pengganti vocal atau melodi ringan. Tidak bisa digunakan untuk memainkan kunci piano atau melodi cepat.

\subsection{Saran}

Dari simpulan dan keterbatasan produk diatas, maka dapat diajukan beberapa saran sebagai bahan 
pertimbangan guna pengembangan lebih lanjut, saran tersebut diantaranya sebagai berikut :

1. Menambahkan jeck hadset atau jeck mic agar output suara dapat dimasukkan ke dalam speaker aktif atau speaker eksternal sehingga suara dapat lebih halus dank eras.

2. Ketika membeli suatu komponen hendaknya mengecek komponen tersebut apakah benar - benar bagus atau bermasalah.

3. Dari rancang banging alat musik melodi tiruan ini, untuk selanjutnya dapat dikembangkan agar dapat digunakan untuk bermain ritem.

\section{DAFTAR PUSTAKA}

Syahwil, Muhammad, 2013; "Panduan Mudah Simulasi \& Praktek Mikrokontroler Arduino", Yogyakarta : Andi.

Setiawan, Agus, 2013; "Cara Main Piano di Komputer dengan Software Everyone Piano", Transiskom,

Kristianto, Nugroho Budhi, Arlistya, 2014; "Alrm Sentuh Jarak Jauh sebagai Alat Keamanan Peternakan Ayam", Salatiga : Universitas Kristen Satya Wacana,

Padnamaba, Galas Sangaluh, 2014; "Metode Pembelajaran Drum Band di Taman Kanak - Kanak Negeri 1 Sleman", Yogyakarta : Universitas Negeri Yogyakarta,

Adi, Dwi Suputera, 2015; "Pemanfaatan Magnetohidrodinamika Sebagai Energi Penggerak (Magnetic Propulsion) Pada Kapal", Jember : Universitas Jember,
Lestiorini, Ari, 2015; "Sistem Pencegah Kebakaran Dengan

Detektor Sensor Asap Mq-7, Sensor Suhu Dht22 Am2302 Dan Aktivasi Kran/Pompa Air Otomatis Menggunakan Arduino Uno R3", Semarang : Stekom.

Rahmat Rahmon Sandika, Firdaus, Erlina Tati, AisuwaryaRatna, 2015; "Rancang Bangun Alat Musik Drum Air Berbasis Mikrokontroller", Padang : Universitas Andalas,

Sirait Van Eko, Betty Lea Belandina, 2015; "Trik A-Z Menguasai PianoThe Best Instruction", Bantul : Indoliterasi.

Andrianto Heri,Darmawan Aan, 2016; "Arduino Belajar Cepat Dan Pemrograman", Bandung: Informatika.

Pujiadi, 2016; "Penelitian Pendidikan Bergenre Research And 